\title{
Health and Nutritional Profile of Working and Non-Working Slum Children
}

\author{
Md Monoarul Haque ${ }^{1 *}$ \\ A K M Majbah Uddin ${ }^{2}$ \\ Md Zahid Hasan Khan ${ }^{3}$ \\ Khaleda Islam ${ }^{4}$
}

${ }^{1}$ Department of Community Nutrition

Faculty of Public Health

Bangladesh University of Health Sciences (BUHS)

Dhaka, Bangladesh.

${ }^{2}$ Department of Public Health \& Life Science University of South Asia

Dhaka, Bangladesh.

${ }^{3}$ Community Medical Institute

Gaibandha, Bangladesh.

${ }^{4}$ Institute of Nutrition and Food Science

University of Dhaka

Dhaka, Bangladesh.

\begin{abstract}
Background: The nutritional status of children does not only directly reflect the socioeconomic status of the family and social wellbeing of the community, but also the efficiency of the health care system, and the influence of the surrounding environment. Objective: The present study is an attempt to assess the health and nutritional profile of working and non working slum children in selected slum in Dhaka. Methods: It was a cross sectional descriptive study. The subjects were selected purposively. The study was conducted among 200 slum children in three slum area of Dhaka city. Anthropometric data such as height and weight of the study subjects were collected by using standard techniques. Nutritional status was measured according to WHO guideline. Result: Most of children came from around 12 year age group and male, female distribution was equal. Most of them was Muslim and their income was $<5000$ taka per month. Underweight $(50 \%, 35 \%)$, normal $(38 \%, 49 \%)$, overweight $(8 \%, 10 \%)$ and obese $(4 \%, 6 \%)$ were among working and non working children respectively. Around $50 \%$ of children did not think food for his own, later and need not cook for his own. Almost all took rice 23times/day. Milk, meat, egg, fruits, noodles and soft drinks did not take 23times/day. Vegetables and pulses were taken randomly. Conclusion: Tackling malnutrition in urban slums requires a holistic approach, especially when targeting populations of school-age children. Recommendation: Intervention programs related to health and nutritional status may be arranged.
\end{abstract}

Key words: Nutritional status; Slum children; Socioeconomic status.

\section{INTRODUCTION}

The School age is the active growing phase of childhood ${ }^{1}$. Primary school age is a dynamic period of physical growth as well as of mental development of the child. Research indicates that health problems due to miserable nutritional status in primary school-age children are among the most common causes of low school enrolment, high absenteeism, early dropout and unsatisfactory classroom performance. The present scenario of health and nutritional status of the school-age children in Bangladesh is very unsatisfactory ${ }^{2}$. Growth monitoring is universally used to assess nutritional status, health and development of individual children, and also to estimate overall nutritional status and health of populations. Compared to other health assessment tools, measuring child growth is a relatively inexpensive, easy to perform and non-invasive process. Geographical relocation from rural areas to urban localities will expose migrants to new environmental challenges. Urban slum dwellers are exposed to poor environmental conditions (overcrowding, poor quality drinking water and sanitation, no removal of waste). Ignorance and difficult conditions of life in the slums are likely to result in improper food habits, low health care use and hygiene awareness and lack of knowledge of the origin of sickness and proper measures for the cure. The situation is further worsened due to lack of necessary health centers, medicines, and health care personnel. Children living under such conditions are at especially high risk for health and nutritional problems.

\footnotetext{
Md Monoarul Haque

Fellow (Teaching \& Research)

Dept of Community Nutrition, Faculty of Public Health Bangladesh University of Health Sciences (BUHS) 125/1, Darus Salam, Mirpur, Dhaka-1216, Bangladesh. Mobile: +8801915839550

E-mail: monoarmunna@yahoo.com
} 
Anthropometric examination is an almost mandatory tool in any research to assess health and nutritional condition in childhood. Physical measurements like body weight, height, circumference of arm and calf, triceps skin fold of children have been extensively used to define health and nutritional status of communities. Based on the age, body weight and height, a number of indices such as height-for-age and weightfor-height have been suggested ${ }^{3}$. The children are classified using three categories: 'underweight' (low weight-for-age), 'stunting' (low height-for-age) or 'wasting' (low weight-forheight). Low anthropometric values are those more than $2 \mathrm{SD}$ away from the CDC 2000 (Centers for Disease Control and Prevention) standards ${ }^{3-6}$. The nutritional status of children does not only directly reflect the socioeconomic status of the family and social wellbeing of the community, but also the efficiency of the health care system, and the influence of the surrounding environment. The present study in selected slums of Dhaka City in Bangladesh, aimed to evaluate the overall health and nutritional profile of working and non working slum children and to recommend measures for correction of the nutritional deficit of the vulnerable population group and to provide baseline data for future research.

\section{MATERIALS \& METHODS}

Study Area: Vasantak, Beribad and Kalimondir slum area

Study Period and Duration: From August 2013 to February 2014

Study Population: The study was conducted among children 6 to 15 years old residing slum area

Study Design: Cross-sectional comparative study

Sample size: Sample size for the study was decided by following equation.

$\mathrm{n}=\mathrm{z} 2 \mathrm{xpqd} 2$

Here

$\mathrm{n}=$ desired sample size

$\mathrm{z}=$ Value of standard normal distribution as given level of significant (confidence level) usually considered value $1.96 \%$ confidence interval $(\mathrm{CI})$

$\mathrm{p}=50 \%$ or $(0.5)$ (As no study found)

$\mathrm{q}=1-\mathrm{P}=(100-50)=50 \%$ or $(0.5)$

$\mathrm{d}=$ degree of accuracy desired, usually set at $5 \%(0.05)$

So by this equation sample size was $n=384$, but due to time constrain and lack of resources I had to take 200 samples (100 working+100 non working)

Sampling technique: Purposive sampling technique was applied

Inclusion and exclusion criteria: Those were willing to participate in the study. Very sick and mentally retarded as well as not willing to participate in the study

Data collocation tool and instrument: Pre-tested semi structure questionnaire, Weight machine and Height measuring scale

\section{Data collection method:}

- Data were collected by pre tested semi structured questionnaires and in face to face interview

- Information about health profile, nutritional profile, diet habit along with socio-demographic characteristics were also obtained

- The field work was conducted from August 2013 to February 2014 in three slum area in Dhaka city

- The respondents were selected consecutively who met the inclusion and exclusion criteria

Data Analysis: Data were analyzed by SPSS 16.0 version of computer technology

\section{RESULTS}

Table1 : Socio-demographic information of children $(n=200)$

Most of children came from around 12 year age group and male, female distribution was equal. Most of them was Muslim and their income was $<5000$ taka per month.

$\begin{array}{lcr}\text { Characteristics } & \text { Frequency } & \text { Percentage } \\ \text { Age group } & & \\ 6-8 & 50 & 25 \\ 9-11 & 40 & 20 \\ 12-14 & 50 & 25 \\ 15-17 & 44 & 22 \\ >17 & 16 & 8 \\ \text { Sex } & & \\ \text { Male } & 100 & 50 \\ \text { Female } & 100 & 50 \\ \text { Religion } & & \\ \text { Muslim } & 193 & 96.5 \\ \text { Hindu } & 6 & 3 \\ \text { Christian } & 1 & .5 \\ \text { Family members } & & \\ <3 & 20 & 10 \\ 3-5 & 166 & 83 \\ >5 & 14 & 7 \\ \text { Family income } & & \\ <5000 \text { BDT } & 116 & 58 \\ 5000-10000 \text { BDT } & 66 & 33 \\ >10000 \text { BDT } & 18 & 9 \\ & & \end{array}$

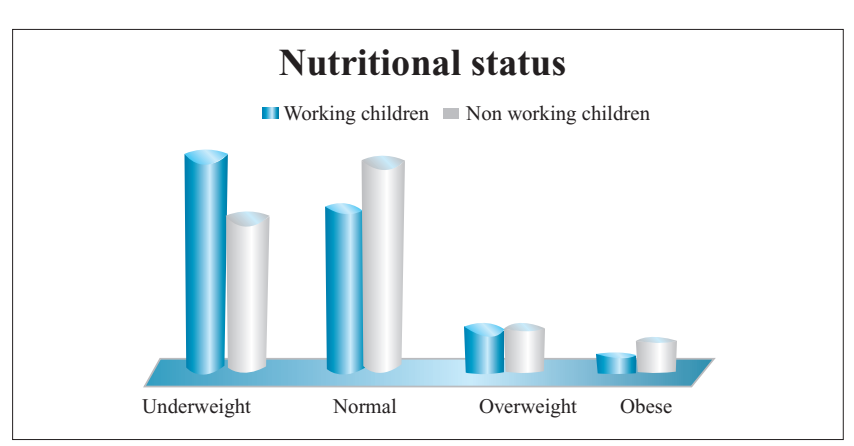

Figure1 : Nutritional status of respondents $(n=200)$

Underweight $(50 \%, 35 \%)$, normal $(38 \%, 49 \%)$, overweight $(8 \%, 10 \%)$ and obese $(4 \%, 6 \%)$ were among working and non working children respectively. 
Table 2 : Work related information of children $(n=200)$

$37.5 \%$ did medium type of work and $40 \%$ of them did 5-8 hour work per day and most of their income was 500-800 BDT per month.

\begin{tabular}{lcr} 
Work & Frequency & Percentage \\
Non working & 100 & 50 \\
Type of work & & \\
Normal & 17 & 8.5 \\
Medium & 75 & 37.5 \\
Heavy & 8 & 4 \\
Working time & & \\
5-8 hour & 80 & 40 \\
$>8$ hour & 20 & 10 \\
Personal income & & \\
$<500$ BDT & 30 & 15 \\
500-800 BDT & 60 & 30 \\
$>800$ BDT & 10 & 5 \\
\hline
\end{tabular}

Table 3 : Hygiene related information of children $(n=200)$

Tinshed house was more. Most of them used sandle during work and toileting. They clean teeth and cut nail regularly. All of them use tubewell water for drink. About half of them used open place for toileting.

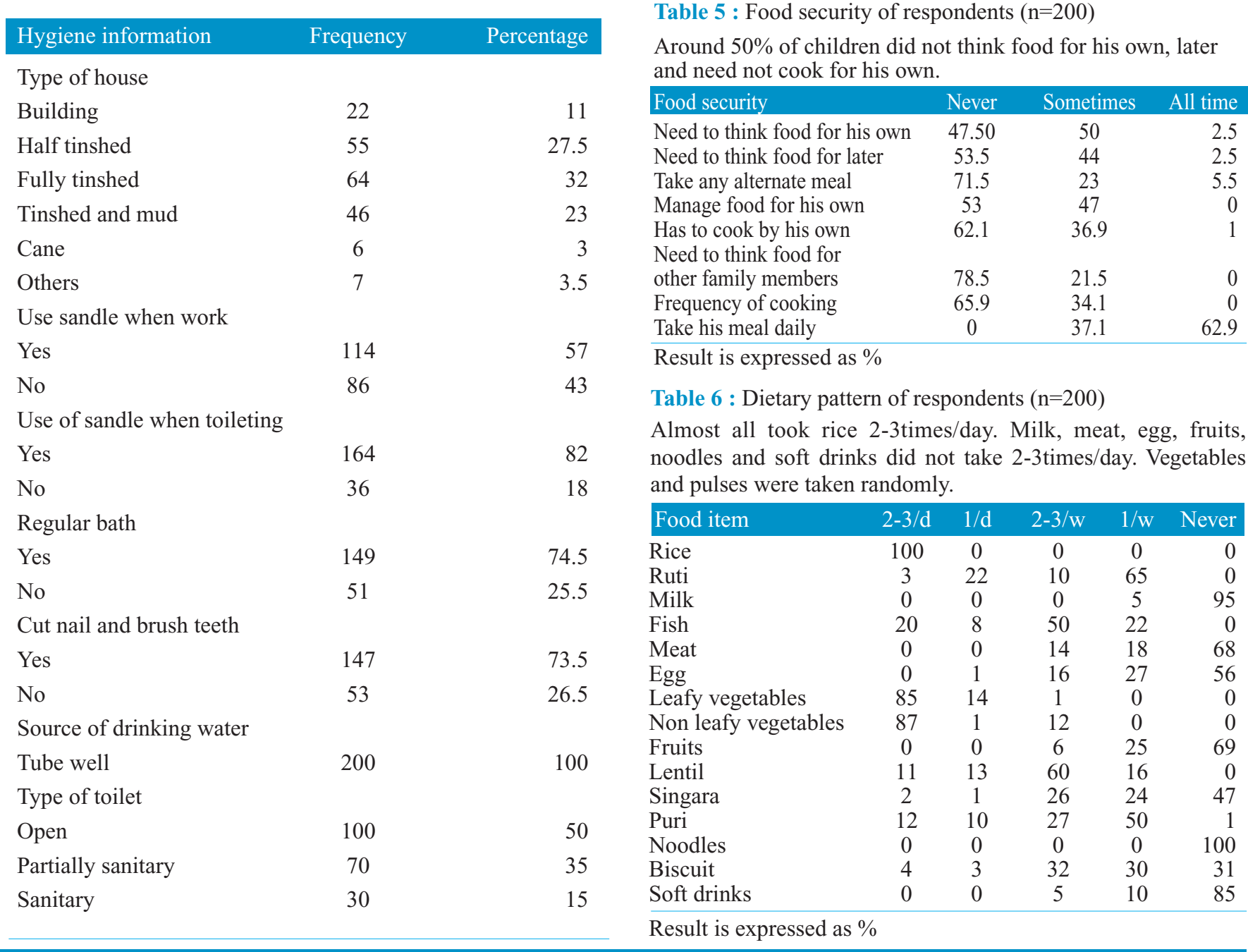

Table 4 : Nutritional knowledge of respondents $(n=200)$

Half of children did not know about nutritional food and nutritious food for healthy body. Half of the children did not know about malnutrition.

$\begin{array}{lcr}\text { Nutritional knowledge } & \text { Frequency } & \text { Percentage } \\ \text { Idea about nutritional food } & & \\ \text { Yes } & 100 & 50 \\ \text { No } & 98 & 49 \\ \text { Don't know } & 2 & 1 \\ \text { Need to take nutritious food for healthy body } & & \\ \text { Yes } & 67 & 33.5 \\ \text { No } & 45 & 22.5 \\ \text { Don't know } & 88 & 44 \\ \text { Knowledge on malnutrition } & & \\ \text { Yes } & 92 & 56 \\ \text { No } & 108 & 76 \\ \text { Got any vaccine yet } & & 24 \\ \text { Yes } & 152 & 64 \\ \text { No } & 48 & 18.5 \\ \text { Got any vitamin capsule yet } & & 16.5 \\ \text { Yes } & 128 & 29 \\ \text { No } & 39 & 46 \\ \text { Don't know } & 33 & 25 \\ \text { Has any nutritional health problem } & & \\ \text { Yes } & 58 & 92 \\ \text { No } & 50 & \\ \text { Don't know } & \end{array}$

Table 5 : Food security of respondents $(n=200)$

Around $50 \%$ of children did not think food for his own, later need not cook for his own.

Table 6 : Dietary pattern of respondents $(\mathrm{n}=200)$

Almost all took rice 2-3times/day. Milk, meat, egg, fruits, and pulses were taken randomly. 


\section{DISCUSSION}

Children in the age group of 5-14 years are often considered as school-age. In it is recorded that in Bangladesh one fifth of the population consists of children between 5 and 14 years, which includes the primary and secondary school age. Hence the present study was formulated with the objective, to assess and find the major socio-economic correlates of nutritional status in school-age children. The present study showed a growth lag in the basic parameters of height and weight as compared to the reference standards laid down by CDC 2000. Our findings are similar to that reported by other workers from India, ${ }^{7,8}$. Best C. et al. also reported that underweight and thinness were most prominent in populations from South-East Asia and Africa, whereas in Latin America, the prevalence of underweight or thinness was generally below $10 \%{ }^{9}$. Throughout the developing world, children fail to grow in length and weight in a remarkably similar age-specific pattern, despite vast differences in the prevalence of low weight (wt)/age and height (ht)/age between the regions ${ }^{2}$. We analyzed the prevalence of stunting, wasting and underweight as markers of under nutrition and our findings were similar as in South Africa, where stunting and underweight remain a public health problem in children, with a prevalence of $20 \%$ stunting and almost $10 \%$ underweight $^{10}$. The anthropometric results of a study in Qwa Qwa also indicated that $2.8 \%$ of the total group of respondents was severely stunted, and that $11.3 \%$ were stunted ${ }^{11}$. Thus the differences in the degree of growth failure in weight and height have implications for assessing the true prevalence of chronic malnutrition. This is also important for monitoring trends or evaluating the effects of interventions ${ }^{12}$. There is a need to shift the focus from wt/age to ht/age and wt/ht for assessing malnutrition and identifying populations that could benefit from interventions. The school children in the present study were found to be better nourished than the rural Punjab school children as reported in another recent study ${ }^{13}$, where the prevalence of malnutrition was $87.4 \%$. However, the standards of nutrition among children in the present study were lower than those found in children in Delhi by Dhingra et al. ${ }^{14}$ and in urban school-age children in Tirupati as reported by Indirabai et al. ${ }^{15}$. Goyal et al. ${ }^{16}$ found malnutrition among Ahmednagar school children to be $20 \%$ only, with $6.8 \%$ having severe malnutrition, which is much lower than rural school children of Punjab (37.6\%) ${ }^{13}$ and amongst school children of Madras, as found by Sunderam et al. $(32.6 \%)^{17}$. These disparities in findings of different studies may be due to differences in study settings. The rate of under nutrition of the present study is quite similar to the findings of Medhi et al. ${ }^{18}$ who recorded a prevalence rate of under nutrition of $53.9 \%$ among school-age children in Assam-India.The evidence suggests that boys are more likely to be stunted and underweight than girls, and in some countries, more likely to be wasted than girls ${ }^{19,20}$, but in the present study, under nutrition was significantly more prevalent in girls than boys. A number of studies in Africa suggest that rates of malnutrition among boys are consistently higher than among girls. Studies conducted in Ecuador ${ }^{21}$ and in Tanzania $^{22}$ show that boys were more commonly affected than girls.
One of the largest studies ${ }^{20}$ of anthropometric status of rural school children in low income countries (Ghana, Tanzania, Indonesia, Vietnam and India) found the overall prevalence of stunting and underweight to be high in all five countries, ranging from 48 to $56 \%$ for stunting and from 34 to $62 \%$ for underweight. Boys in most countries tended to be more stunted than girls and in all countries, boys were more underweight than girls. These disparities in findings are due to differences in study frame, family setups, gender bias and parental preferences for male children in the Indian society.

Women's educational and social status, food availability, and access to safe water are well reported important underlying determinants that directly or indirectly cause malnutrition among children ${ }^{23}$. In our study mother's education was found to be a strong predictor of child nutritional status. Data analysis of National Family Health Survey (NFHS) 1 also showed that mother's education has a strong independent effect on a child's nutritional status even after controlling for the potentially confounding effects of other demographic and socioeconomic variables $^{24}$. Earlier studies using household-level data have found mother's education to be positively associated with a number of measures of child health and nutritional status ${ }^{25-31}$. Results pointing to the importance of socioeconomic status indicators such as mother's education to children's nutritional status are consistent with findings in Yip et al. ${ }^{32}$. Further improvement in nutritional status with maternal education has been reported by other authors ${ }^{33-36}$. The pattern of declining incidence of stunting by mother's education in Cambodia is consistent with patterns observed in many other developing countries $^{37}$. The pattern for wasting concurs with arguments found in several other studies ${ }^{38,39}$ that wasting is influenced less by maternal characteristics than is stunting. One explanation is that mother's education has a limited effect on preventing illness such as diarrhea when there are widespread sources of infection. Various studies have concluded that parental education, especially mothers' education, is a key element in improving children's nutritional status ${ }^{40,41}$. One of the strongest predictors of malnutrition in this analysis was mother's working status. Children of nonworking mothers have better nutritional status than children of working mothers, possibly due to more time for caring of children ${ }^{34,35}$.

\section{CONCLUSION}

It is clear that the problem of malnutrition in Bangladesh is of alarming magnitude, but also of great intricacy. A major part of this problem is contributed by slum population. Tackling malnutrition in urban slums requires a holistic approach, especially when targeting populations of school-age children.

\section{DISCLOSURE}

All the authors declared no competing interest. 


\section{REFERENCES}

1. Nutrition for the school-aged child NebGuide Series No.G92-1086-A 2002,1.

2. International Institute of Population Sciences (IIPS) National Family Health Survey (NFHS-3), Fact sheets for 29 States Mumbai: International Institute for Population Sciences India, Mumbai 2007.

3. Waterlow IC, Buzina R, Keller W, Lane IM, Nichaman MZ, Tanner IM: The presentation and use of height and weight data for comparing the nutritional status of groups of children under the age of 10 years. Bull World Health Organ 1977, 55:489-498. PubMed Abstract | PubMed Central Full Text.

4. Kuczmarski RJ, Ogden CL, Guo SS, Grummer-Strawn LM, Flegal KM, Mei Z, et al.: 2000 CDC Growth Charts for the United States: methods and development. Vital Health Stat. 2002; 11(246):1-190.

5. WHO Expert Committee on Physical Status: Physical status: the use and interpretation of anthropometry, report of a WHO expert committee. Geneva, World Health Organization 1995.(WHOTechnicalReportSeries,No.854.

6. Anurag Srivastava, Syed E Mahmood, Payal M Srivastava, Ved P Shrotriya and Bhushan Kumar. Nutritional status of school-age children - A scenario of urban slums in India. Archives of Public Health. 2012; 70:8.

7. Panda P, Benjamin AI, Singh S, Zachariah P: Health status of school children in Ludhiana city. Indian J Community Med. 2000; 25(4):150-155.

8. Banerjee A: Height and weight patterns as indicators of growth among school children in an Air Force Station: A cross sectional study. Med J Armed Forces India. 2001; 57(1):8-11.

9. Best C, Neufingerl N, Van Geel L, Van den Briel T, Osendarp S: The nutritional status of school-aged children: why should we care? Food Nutr Bull. 2010; 31(3):400-417.

10. Labadarios D, Swart R, Maunder EMW, Kruger HS, Gericke GJ, Kuzwayo PMM, Ntsie PR, Steyn NP, Schloss I, Dhansay MA, Jooste PL, Dannhauser A, Nel JH, Molefe D, Kotze YJVW: Executive summary of the national food consumption survey fortification baseline (NFCS-FB-1) South Africa, 2005. S Afr J Clin Nutr. 2008; 21(Suppl 2):245-300.

11. Oldewage-Theron WH: B Egal AA, Nutrition knowledge and nutritional status of primary school children in QwaQwa. S Afr J Clin Nutr. 2010; 23(3):149-154

12. Gopalan C, Harvinder Kaur: Towards Better Nutrition - Problems and Policies. Nutrition Foundation of India, Special Publication Series. 1993; 9:70-78.

13. Panda P, Benjamin AI, Zachariah P: Growth and morbidity patterns among rural school children in Ludhiana, Punjab. Health Popul Perspect Issues. 1997; 20(1):20-28.

14. Dhingra DC, Anand NK, Gupta S: Health status of school children of various socio-economic groups. Indian Pediatr. 1977; 14(3):243-246.

15. Indirabai K: Ratna Malika DPNM: school health service programme, a comprehensive study of school children of Tirupati city, Andhra Pradesh. Indian Pediatr. 1976; 13(10):751-758.

16. Goyal RC, Chavan UA: Health status of school children in Ahmednagar city. Indian J Maternal Child Health. 1993; 4(3):81-83.

17. Sunderam VM: Health profile of school children in Madras city. Indian Pediatr. 1978; 15(9):725-730.

18. Medhi GK, Barua A, Mahanta J: Growth and nutritional status of school age children (6-14 years) of tea garden worker of Assam. J Hum Ecol. 2006; 19:83-85.

19. Shahabuddin AKM, et al.: Adolescent nutrition in a rural community in Bangladesh. Indian J Pediatr. 2000; 67(2):93-98.

20. Partnership for Child Development: The anthropometric status of school children in five countries in the Partnership for Child Development. Proc Nutr Soc. 1998; 57:149-158.

21. Sebastion MS, Senti S: The health status of rural school children in Amazon Basin of Ecuador. J Trop Pediatr. 1999; 45:379-382.

22. Lwambo N, Brooker S, Siza J, et al.: Age patterns in stunting and anemia in African school children, A cross sectional study in Tanzania. Eur J Clin Nutr. 2000; 54:36-40.

23. Smith LC, Haddad L: Explaining Child Malnutrition in Developing Countries A Cross- Country Analysis. [http://www.ifpri.org/pubs/abstract/111/rr111.pdf] webcite International Food Policy Research Institute, Washington, D.C.; 2000.

24. Mishra VK, Retherford RD: Women's education can improve child nutrition in India. NFHS Bulletin. 2000; 15:7-10.

25. Bicego GT, Boerma JT: Maternal education and child survival: a comparative study of survey data from 17 countries. Soc Sci Med. 1993; 36(9):1207-1227.

26. Thomas D, Strauss J, Henriques M-H: How does mother's education affect child height? J Hum Resour. 1991; 26:183-211.

27. Hobcraft J: Women's education, child welfare and child survival: a review of the evidence. Health Transit Rev. 1993; 3(2):159-173

28. Miller J, Korenman S: Poverty children's nutritional status in the United States. Am J Epidemiol. 1994; 140(3):233-243.

29. Desai S, Alva S: Maternal education and child health: is there a strong causal relationship? Demography. 1998; 35(1):71-81. 


\section{REFERENCES}

30. Boyle M, Racine Y, Georgiades K, Snelling D, Hong S, Omariba W, Hurley P, Rao-Melacini P: The influence of economic development level, household wealth and maternal education on child health in the developing world. Soc Sci Med. 2006; 63:2242-2254.

31. Waters H, Saadah F, Surbakti S, Heywood P: Weight-for-age malnutrition in Indonesian children, 1992-1999. Int J Epidemiol. 2004; 33(3):589-595.

32. Yip R, Scanlon K, Trowbridge F: Improving growth status of asian refugee children in the United States. JAMA. 1992; 267(7):937-940.

33. Mukuria A, Cushing J, Sangha J: Nutritional status of children: results from the demographic and health surveys 1994-2001. DHS Comparative Reports ORC Macro; Calverton, Maryland. 2005; 10:35-36.

34. Katahoire A, Scheutz F, Sabroe S, Whyte SR: The importance of maternal schooling for child morbidity and mortality and maternal health behavior in Southeastern Uganda. J Health Popul Dev Ctries. 2004; 6:1-12.

35. Frost MB, Forste R, Haas DW: Maternal education and child nutritional status in bolivia: finding the links. Soc Sci Med. 2005; 60(2):395-407.

36. Christiaensen L, Alderman H: Child malnutrition in Ethiopia: can maternal knowledge augment the role of income? Econ Dev Cult Chang. 2004; 52(2):287-312.

37. Moen AA: The impact of child and maternal survival programmes on socio-economic development. Center for Economic Research on Africa: School of Business, Montclair State University, Upper Montclair, New Jersey; 1993.

38. Bishnoi P, Sehgal S, Kwatra A: Anthropometric measurements of preschool children as effected by socio-economic factors. Asian Pac J Clin Nutr. 2004; 13:132.

39. Gopaldas T, Patel P, Bakshi M: Selected socio-economic, environmental, maternal, and child factors associated with the nutritional status of infants and toddlers. Food Nutr Bull. 1998; 10:29-34.

40. Shah SM, Selwyn BJ, Luby S, Merchant A, Bano R: Prevalence and correlates of stunting among children in rural Pakistan. Pediatr Int. 2003; 45:49-53.

41. Ray SK, Biswas AK, Gupta SD, Mukerjee D, Kumar S, Biswas B, Joardar G: Rapid Assessment of nutritional status and dietary pattern in a municipal area. Indian J Community Med. 2000; 1:7-10. 